\title{
Understanding How Chemistry Teachers Transform Stoichiometry Concepts at Secondary Level in Lesotho
}

\author{
Mamohato Makhechane and Makomosela Qhobela* (iD ${ }^{\S}$ \\ Department of Science Education, National University of Lesotho, Lesotho. \\ Received 21 July 2018, revised 1 February 2019, accepted 2 February 2019.
}

\begin{abstract}
This qualitative study sought to investigate how secondary level chemistry teachers transform and represent subject matter knowledge (SMK). The study drew its theoretical framework from the notion of Pedagogical Content Knowledge (PCK) that foregrounds the teachers' ability to transform and represent SMK for students to understand the content presented. Seven qualified chemistry teachers participated in this study which used questionnaires, follow-up interviews, and lesson observations to collect data. The teachers were observed teaching the topic of stoichiometry to grade 11 students. Data analysis started with a coding system that resulted in themes of meanings suggested by teachers. The results show that chemistry teachers participating in the study were aware of different teaching strategies but their choice of those strategies was not informed by an attempt to transform the concepts. It is argued that teachers' failure to transform concepts will have a negative impact on students' understanding of these concepts.
\end{abstract}

KEYWORDS

Teaching strategies, PCK, chemistry, stoichiometry.

\section{Introduction}

Underachievement in mathematics and science, both at primary and secondary levels, remains a challenge worldwide $\mathrm{e}^{1,2}$ including in Lesotho. ${ }^{3}$ Many studies have discussed different factors resulting in underachievement in mathematics and science in developed and developing countries. For instance, there are researchers who have argued that underachievement in science is a result of unavailability and/or adequacy of infrastructure and quality of teaching. ${ }^{4}$ In Lesotho, achievement has been related to factors such as teaching experience of teachers, provision and attendance at professional development initiatives, and availability of teaching and laboratory materials. ${ }^{5}$ Another contributing factor is the choice and use of teaching approaches ${ }^{6}$. It has been argued that teachers tend to use chalk and talk strategies that inevitably socialize students into sitting down and watching the teacher, ${ }^{6,7}$ thus, becoming one of the contributing factors toward low student performance in science in general and in chemistry in particular. Research also shows that students in Lesotho sometimes progress to tertiary level having had no opportunity of doing basic experiments in chemistry. ${ }^{8}$

Literature shows that stoichiometry is considered a difficult and abstract topic to teach and learn in chemistry. ${ }^{9}$ Anecdotal evidence suggests that many teachers in Lesotho struggle with the teaching of stoichiometry and that many students do not perform well in stoichiometry questions in external examinations. Research elsewhere shows that stoichiometry demands special efforts from teachers to develop effective teaching strategies $^{10}$, drawing on their topic specific Pedagogical Content Knowledge (PCK). ${ }^{11,12}$

This study explored the construct of PCK within the context of science education in Lesotho. The purpose of this study was to investigate how secondary level chemistry teachers transform and represent subject matter so that effective teaching and learning can occur. This paper responds to the following

* To whom correspondence should be addressed. E-mail: qhobela @yahoo.com research question: How do chemistry teachers in Lesotho transform subject matter when teaching stoichiometric concepts at senior secondary level so that these are easily understood by students? This research question was divided into three subquestions, namely:

- What is the influence, if any, of the simplification of concepts on teachers' choice of their teaching strategies?

- What do the teachers do to simplify stoichiometry concepts in their lesson? and

- What influenced teachers' identification of big ideas of stoichiometry?

Although there is literature on the issues of learner-centred teaching of science in Lesotho there was a need to understand teaching practice from a different perspective, namely PCK. The contribution of this study therefore is that of describing teaching strategies used in Lesotho to teach stoichiometry.

\section{Literature Review}

\subsection{Pedagogical Content Knowledge}

Teaching for student understanding needs a special form of knowledge that will enable teachers to transform content knowledge into forms more accessible to students; this type of knowledge Shulman ${ }^{13}$ referred to as PCK. According to Shulman the development of PCK involves shifting:

'from being able to comprehend subject matter for themselves, to being able to clarify subject matter in new ways, reorganize and partition it, clothe it in activities and emotions, in metaphors and exercises, and in examples and demonstrations, so that it can be grasped by students (p. 13)

The central theme of the construct of PCK is the notion of making the subject matter comprehensible to students. Many researchers have studied aspects of PCK, and two of these are described below. 
Mavhunga \& Rollnick proposed a model which considers PCK as a construct at the level of the topic, namely Topic-Specific PCK. ${ }^{14}$ This model views transformation of content knowledge through five components; namely Learners' Prior Knowledge, Curricular Saliency, What makes a topic easy or difficult to understand, Representations including analogies and Conceptual Teaching Strategies'. ${ }^{14}$ According to the researchers, if science teachers, when planning teaching, consider these components their teaching is likely to make concepts easier to understand.

Another conceptualization of PCK refers to an amalgam of teachers' different knowledge areas such as subject matter knowledge, pedagogical knowledge and contextual knowledge. ${ }^{15}$ According to this view the process of making the subject matter comprehensible to learners, requires bringing together different knowledge areas. For instance, some researchers argue that a teacher has to bring together five knowledge areas: the teacher's orientations to science teaching, knowledge of students' understanding in science, knowledge of science curriculum, knowledge of instructional strategies and representations for teaching science, and knowledge of assessments of science learning. ${ }^{16}$ On the other hand, it has been argued that for the situation in Lesotho, physics teachers need to bring together, at the very least, subject matter knowledge, pedagogical knowledge and contextual knowledge to make concepts understandable to students. ${ }^{17}$

Every teacher's knowledge area plays a special role in the teaching and learning of science but the following are explored in this study: orientations to science teaching including beliefs about goals and purpose of science teaching, the role of prior knowledge and practical work, and beliefs about what makes a good and effective science teacher.

Several studies have sought to capture and portray teachers' ability to transform the subject matter. Loughran and colleagues suggested an approach of how teachers can transform the subject matter using the concepts of Content Representation (CoRe) and Pedagogical and Professional experience Repertoires (PaP-eRs).$^{18} \mathrm{~A}$ CoRe illustrates the '...teachers' understanding of particular aspects of PCK... ${ }^{18}$ A critical prompt in a CoRe is 'what are the big ideas for a given topic' since the response to it allows the teacher to critically identify and arrange themes within a topic. PaP-eRs '... are about teaching that content in that context and help to illustrate aspects of PCK in action..$^{18}$ The links between a CoRe and PaP-eRs are critical since they illustrate the '...decisions underpinning the teacher's actions intended to help the learners better understand the content...'.18 This approach has been adopted for this study.

\subsection{Stoichiometry}

Stoichiometry concepts taught at secondary level, mostly for grade 11 and grade 12, involve problem-solving and under- standing of chemical reactions and equations. ${ }^{19,20}$ There is consensus in the literature that many students find stoichiometry concepts difficult because they are highly mathematical and abstract in nature, and require the ability to make connections between symbolic, submicroscopic and macroscopic levels. ${ }^{19,21,22}$ Inevitably, effective teaching of stoichiometry must target some of these learning obstacles. The literature on the teaching of stoichiometry shows that effective teaching of stoichiometry must include promotion of active learner construction of knowledge; be mindful of learners' limited processing capacity; and provide multiple opportunities for encoding information. ${ }^{19,23}$ Again it suggests that if students are allowed to engage with material using multiple representations their understanding of stoichiometry concepts improves. ${ }^{19}$ For students to master the concepts of stoichiometry, they should master the chemistry concepts and be proficient in using balanced equations to calculate the mass, volume, moles and concentration of different substances. ${ }^{11}$

\section{Methodology}

\subsection{Research Design}

The purpose of this study necessitated a qualitative approach. The operational definition of PCK suggests that effective teaching leads to understanding of concepts which in turn might have an impact on performance. Thus, the study paid attention to how teachers taught a topic of stoichiometry at secondary level. To uncover chemistry teachers' PCK, classroom observations, follow-up interviews, and a questionnaire were employed to collect data. The design of this study was guided by two theoretical perspectives from the literature. ${ }^{14}$ Firstly, literature reports that the difficulty associated with recognizing and articulating PCK leads to the need to determine the enactment of PCK through classroom observations. Secondly, completion of CoRes also has potential of determining the enactment of PCK. Questionnaires and interviews were used in order for teachers to explain their actual practice.

\subsection{Sample}

Seven secondary level teachers, from five schools in BothaBothe district, participated in the study. All teachers had chemistry as one of their teaching subjects. Demographic data for the teachers are summarized in Table 1.

The selection of teachers was based on two criteria. Firstly, the teachers had to be prepared to sign consent forms to show that they were willing to participate and reflect on their personal experiences. Secondly, teachers were selected on the basis of convenience of access to the schools.

\subsection{Data Collection}

The conceptualizations of PCK, transformation and amalga-

Table 1 Characteristics of the participating teachers.

\begin{tabular}{|c|c|c|c|c|c|}
\hline \multirow[t]{2}{*}{ Teacher } & \multirow[t]{2}{*}{ Gender } & \multirow[t]{2}{*}{ Age range } & \multicolumn{2}{|c|}{ Qualification } & \multirow{2}{*}{$\begin{array}{l}\text { Teaching experience } \\
\text { (teaching chemistry) }\end{array}$} \\
\hline & & & Degree & Major & \\
\hline $\mathrm{T} 1$ & Male & 40 to 50 & BSc Ed & Chemistry and Biology & 19 years \\
\hline $\mathrm{T} 2$ & Female & 30 to 40 & BSc Ed & Chemistry and Biology & 8 years \\
\hline T3 & Male & 30 to 40 & BSc plus PGDE & Chemistry and Biology & 2 years \\
\hline $\mathrm{T} 4$ & Male & 30 to 40 & Dip. in Ed & Chemistry & 4 years \\
\hline T5 & Female & 30 to 40 & BSc Ed & Chemistry and Biology & 10 years \\
\hline T6 & Male & 30 to 40 & Dip. in Ed & Chemistry & 5 years \\
\hline $\mathrm{T} 7$ & Female & 30 to 40 & BSc plus PGDE & Chemistry and Biology & 10 years \\
\hline
\end{tabular}


mation of teacher knowledge areas, require multiple data collection strategies. Three data collection instruments were used: questionnaires, ${ }^{18}$ interviews and lesson observations. Table 2 indicates the data sources for each teacher. For the questionnaire, administered first, teachers had to identify three big ideas of stoichiometry and respond to $\mathrm{CoRe}^{18}$ prompts with the intention of unpacking their understanding of aspects of teaching of stoichiometry. Since the CoRe is not a familiar tool and can be challenging to understand, all seven teachers were given a brief introduction during which the purpose and meaning of each prompt was explained by the first researcher. The following are the CoRe prompts in the questionnaire:

- Identify three main big ideas for the topic of stoichiometry

- What do you intend the learners to know about this idea?

- Why is it important for learners to know this big idea?

-What concepts need to be taught before teaching this big idea?

- What else do you know about this idea (that you do not intend learners to know yet)?

- What do you consider easy or difficult in teaching this big idea?

- What are the typical students' misconceptions on this big idea?

- What effective teaching strategies would you use to teach this topic?, and

- What representations would you use in your teaching strategies?

This questionnaire assisted the researchers to understand what teachers do, specifically at the lesson planning stage, to make concepts of stoichiometry understandable to students. The questionnaire was analyzed and follow-up interview questions were formulated. Three teachers (T1, T2, and T3) were interviewed and all interviews were audio recorded. The choice of teachers to be interviewed was based on their teaching experience and willingness to be interviewed. T1 represented teachers with most experience, T2 represented teachers with moderate experience and $\mathrm{T} 3$ represented teachers with the least experience. The interview data specifically assisted in illuminating the teachers' conceptualization of how to make concepts of stoichiometry easy to understand. Since PCK is tacit and elusive and its different aspects may unfold as a teacher teaches to the same group of students on different days ${ }^{15,24}$ two teachers (T1 and T3) were observed teaching the whole topic of stoichiometry (8 lessons for T3 and 10 lessons for T1). T1 was observed teaching 35 grade 11 students while T3 was teaching 40 grade 11 students. T2 was not observed because of time-table challenges.

Table 2 Data sources.

\begin{tabular}{lccc}
\hline \multirow{2}{*}{ Teacher } & \multicolumn{3}{c}{ Type of data collected } \\
\cline { 2 - 4 } & Questionnaire & Observations & Follow-up interviews \\
\hline T1 & $\checkmark$ & $\checkmark$ & $\checkmark$ \\
T2 & $\checkmark$ & X & $\checkmark$ \\
T3 & $\checkmark$ & $\checkmark$ & $\checkmark$ \\
T4 & $\checkmark$ & $X$ & X \\
T5 & $\checkmark$ & $X$ & X \\
T6 & $\checkmark$ & $X$ & X \\
T7 & $\checkmark$ & $X$ & X \\
\hline
\end{tabular}

$\mathrm{X}=$ Data not collected, $\boldsymbol{V}=$ Data collected .

All lesson observations were audio taped.

\subsection{Data Analysis}

The two conceptions of PCK, namely the transformation and amalgamation of teacher knowledge areas, dictated a data anal- ysis strategy that concentrated on how teachers transform SMK, both at the planning and implementation stage, or bring together the teacher's knowledge of how to make concepts easy to understand. Thus, the first step was to establish teaching strategies that teachers prefer and the justification(s) for their use. The central question was whether teachers use a teaching strategy with the purpose of making stoichiometry concepts understandable to students. Teaching strategies preferred by more than four teachers were noted and their justifications from the interviews were analyzed with emphasis on meaning(s) constructed and/or signalled. The teachers' big ideas are shown in Table 3 and the factors which influenced them to adopt the big ideas were classified into categories. Lesson observations were analyzed using two strategies. The first was to identify meaning(s) signalled by the talk between the teacher and the students and the second was to identify the activities teachers spent time on during the lesson. The first researcher carried out the initial analysis and the second researcher validated the results. Discrepancies in coding responses were resolved through discussion.

\section{Results}

\subsection{Teachers' Big Ideas of Stoichiometry}

The first prompt of CoRe required teachers to list three of their big ideas of stoichiometry. All teachers, as shown in the Table 3, identified three big ideas of stoichiometry except T4 who only listed two.

Table 3 shows that the following big ideas were common to most teachers: calculations of mass, calculations of moles, calculations of volume and concentration. All these big ideas mentioned by the teachers can be considered as big ideas of stoichiometry as knowledge of these concepts can help students deal with stoichiometric related questions. It is also important to note that teachers such as T1, T5 and T7 who just said 'mole' actually meant calculation of moles as inferred from the second prompt. This was also the case for use of the terms mass, volume and concentration. For instance, T1 when answering the second prompt (What do you intend the students to know about this idea) responded as shown in Fig. 1.

An important consideration is what influenced teachers to develop these as their big ideas of stoichiometry. When teachers were interviewed, they gave different explanations of the origin of the big ideas including syllabus, textbooks and experience. The discussion between the researcher, $\mathrm{R}$, and $\mathrm{T} 1$ follows below.

For all extracts from transcripts of the interviews bold type represents translation from Sesotho, ... represents inaudible comments and italics represent a comment.

$\mathrm{R}$ eh, how do you select the content that needs to be covered in stoichiometry?

T1 I just use the syllabus. I am guided by the syllabus.

$\mathrm{R}$ so the syllabus is the only thing that you used.

T1 yes, (laughing) because if I do not use it, then I will be out of the syllabus.

$\mathrm{R} \quad$ why do you have to use the syllabus?

T1 Is it so, I have to teach what is required by the syllabus not by, eh, I mean following everything in the textbooks? (laughing).

$\mathrm{R}$ eh...

T1 no I have to be guided by the syllabus.

In the discussion above, T1 believes that he should not teach anything that is not in the syllabus. Therefore, his big ideas are influenced by the knowledge of curriculum. The discussion with $\mathrm{T} 2$ is described below: 


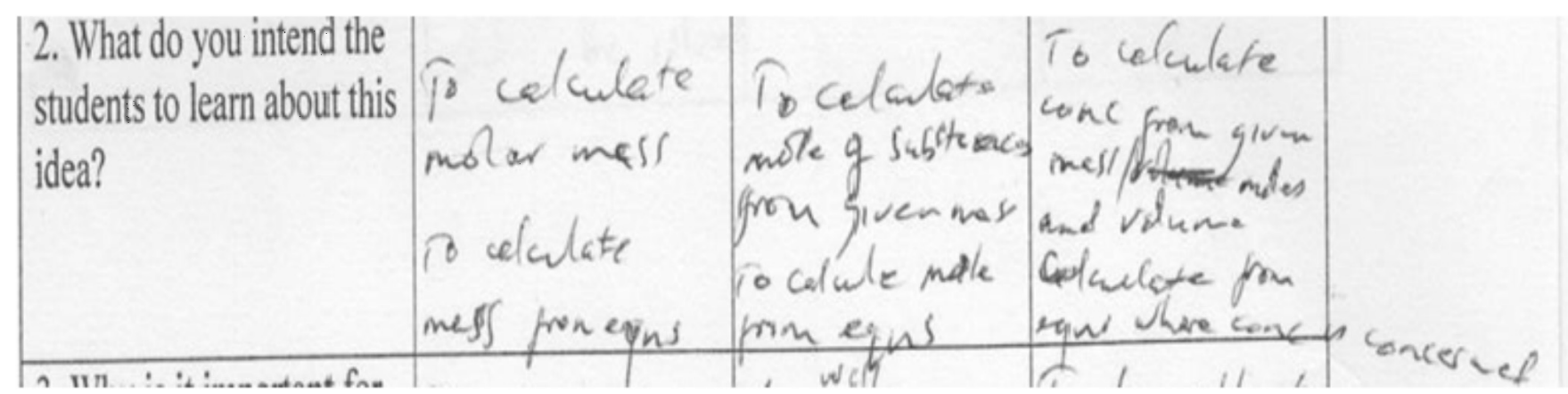

Figure $1 \mathrm{~T} 1$ 's response to a prompt in the questionnaire.

Table 3 Chemistry teachers' big ideas of stoichiometry.

\begin{tabular}{llll}
\hline Teacher & Big Idea 1 & Big Idea 2 & Big Idea 3 \\
\hline T1 & Mass & Mole & Concentration \\
T2 & $\begin{array}{l}\text { Theory about chemical combination } \\
\text { Relation between 1 mole of a substance } \\
\text { T3 }\end{array}$ & $\begin{array}{l}\text { Measurements of chemical quantities } \\
\text { Relation between 1 mole of a gas and } \\
\text { volume }\end{array}$ & $\begin{array}{l}\text { Handling and working with data } \\
\text { Measuring moles in solutions }\end{array}$ \\
T4 & Define mole using Avogadro's constant & $\begin{array}{l}\text { Stoichiometric calculations on reacting masses } \\
\text { and volumes of gases }\end{array}$ & Mass, volumes and concentrations of \\
T5 & RAM and RMM & Mole and Avogadro's constant & solutions \\
T6 & Balancing the equations/ratios & Calculating number of moles & Chemical reactions \\
T7 & Writing formulae & Mole & Chemation of mass
\end{tabular}

T2 I look at the syllabus (laughing). I can also refer to the past question papers.

$\mathrm{R}$ OK, the syllabus and the past question papers meaning you do not cover anything outside the syllabus?

T2 No, I don't.

$\mathrm{T} 2$ relies on the syllabus and questions in past examination papers to select the content to be taught. He argues that he does not teach anything outside the syllabus which implies that his big ideas are prescribed in the syllabus and often tested in the examinations. Thus, the big ideas of T2 are influenced by knowledge of curriculum and assessment. The discussion on the same issue with $\mathrm{T} 3$ went as follows:

T3 OK, yes the syllabus of course will guide us as to what are the requirements, what the students need to know and the textbooks I think do help. The syllabus, the textbooks plus the knowledge that one already has gained...

$\mathrm{R}$ OK.

T3 they are very helpful in...choosing and organizing what the learners have to know.
The extract above shows the origin of T3's big ideas as the syllabus, textbooks, and experience. It is not clear, however, which of the teacher's knowledge base is being referred to but these resources help T3 to choose and organize what students must learn. Thus, for T3 big ideas are influenced by knowledge of curriculum.

None of the teachers made reference to knowledge of subject matter as a contributor to their big ideas of stoichiometry.

\subsection{Choice of Teaching Strategies}

In the questionnaire, the teachers were asked to state the teaching strategies they use to teach stoichiometry. The justifications of the teaching strategies were discussed with them during the interviews. Table 4 summarizes the teaching strategies that teachers mentioned.

The dominant strategies teachers identified were problem solving $(n=5)$, lecturing $(n=4)$, and experimentation $(n=4)$. The extract below shows a discussion between the first researcher and $\mathrm{T} 1$ about the importance of lecturing.

Table 4 Suggested teaching strategies.

\begin{tabular}{|c|c|c|c|c|c|}
\hline Teacher & Lecturing & Problem solving & Experimentation & Questions and answer & Discussion \\
\hline $\mathrm{T} 1$ & $\checkmark$ & $x$ & $X$ & $x$ & $\checkmark$ \\
\hline $\mathrm{T} 2$ & $x$ & $\checkmark$ & $\checkmark$ & $\checkmark$ & $x$ \\
\hline $\mathrm{T} 3$ & $\checkmark$ & $\checkmark$ & $x$ & $\checkmark$ & $x$ \\
\hline $\mathrm{T} 4$ & $\checkmark$ & $\checkmark$ & $\checkmark$ & $x$ & $x$ \\
\hline $\mathrm{T} 5$ & $x$ & $\checkmark$ & $x$ & $\checkmark$ & $\checkmark$ \\
\hline $\mathrm{T} 6$ & $x$ & $\checkmark$ & $\checkmark$ & $x$ & $x$ \\
\hline $\mathrm{T} 7$ & $\checkmark$ & $x$ & $\checkmark$ & $x$ & $\checkmark$ \\
\hline Frequency & 4 & 5 & 4 & 3 & 3 \\
\hline
\end{tabular}

$X=$ No strategy suggested, $\checkmark=$ Strategy adopted. 
$\mathrm{R}$ Why is lecturing important in the teaching of stoichiometry? Why not other methods?

T1 I cannot say it is important, but since the topic (stoichiometry) is too abstract, then I think that is the reason why lecturing is the...maybe the best option.

R OK Sir. Eh, how does this contribute...this lecturing...how does it contribute to students' understanding of this topic and maybe chemistry in general?

T1 ...well it helps students to understand, even though not that well, unlike when you...maybe when they are carrying out experiments, but it still helps them understand, since there is not, there are not many experiments that can be done to do those calculations.

In the extract above two issues are highlighted. Firstly, T1 argues that the abstract nature of stoichiometry concepts dictates the use of lecturing which may be seen as understanding of the subject matter. Secondly, T1 acknowledges that lecturing may not be as effective as other methods such as experimentation. T1 does not show, however, what he does to maximize the effectiveness of lecturing.

The discussion with T2 about the same matter follows:

$\mathrm{R}$ Why is lecturing important in the teaching of stoichiometry?

T2 because they don't know anything on the, on the concept...

$\mathrm{R}$ OK...

T2 you have to, to, to, to tell them.

$\mathrm{R}$ OK. Eh how does lecturing contribute to students' understanding of this topic?

T2 yes I think they understand.

T2 seems to subscribe to a view that communicating with students in a form of lecturing enables students to understand stoichiometry concepts. His view seems to come from his knowledge of students but does not show how lecturing to them addresses the situation.

The extract below shows what $\mathrm{T} 3$ said about the importance of experimentation.

$\mathrm{R}$ OK, eh the last one was experimentation. How is it important?

T3 ...sometimes teachers might want to do experiments in which they want to prove to the students about for example, percentage composition of elements in compounds...

In the extract above $\mathrm{T} 3$ uses the verification role of practical work to justify use of experimentation in the teaching of stoichiometry. The discussion with $\mathrm{T} 2$ about the role of practical work is described below:

T2 I have never done it...(smiling)

$\mathrm{R}$ so you don't know?

T2 maybe I'm still not teaching properly...(laughing)...but I have never used experimentation in this topic.

R OK...

$\mathrm{T} 2$ acknowledges that he has never used experimentation to teach stoichiometry. His utterance, 'maybe I'm still not teaching properly...' suggests somebody who realizes the importance of experimentation in the teaching of stoichiometry.

The discussion between the first researcher and T2 about the importance of problem solving is shown in the extract below.

$\mathrm{T} 2 \mathrm{OK}$, sometimes it will be just reading a question to them....and then they will work it out individually and the student who has finished will raise a hand and give the answer. And the ones who are confused, you will see them that they are not working out...

$\mathrm{R}$ so students are given the question that they then give the response to...

T2 yes they give the response...
The extract above shows how problem solving is used and why teachers find it helpful. T2 says he gives a problem to students to solve and students who are not following will not do their work. In the extract below, T3 also highlights the importance of problem solving.

T3 ...when you want to assess the students in class...you need to ask the questions in which they can really answer you in class so that you keep track of their progress.

T3 confirms T2's idea that problem solving helps the teacher to assess students' progress during the lesson which highlights his knowledge of assessment not just as a way of giving students grades but as used during teaching.

It is important to note that both teachers' lessons were dominated by lecturing and students were given problems to practise towards the end of the lesson.

\subsection{Making Concepts of Stoichiometry Easy to Understand}

What chemistry teachers did to make concepts of stoichiometry easy was determined by analysing what happened in the lessons. The lessons of both teachers (10 lessons of T1 and 8 lessons of T3) were similar in terms of their format of delivery. In general, all the lessons had an introduction stage where the concept was explained following a lecture format and followed by a problem solving stage. Then students were asked to solve one or more problems as a way of giving them practice, and the teacher moved from one student to another marking and assisting them individually. Incidences where the teachers were presumed to be making the concepts easy could be classified into two categories.

The first category was the use of analogies and/or representations to introduce the concepts. ${ }^{14,25,14}$ The extract below, taken from $\mathrm{T1}$ 's lesson on concentration, shows what happened.

T1 What do we mean by the term concentration? In the laboratory, we usually talk about solutions being concentrated and in supermarkets when you buy drink like Oros. What do you usually do before you can drink it?

Sts (in chorus) dilute it.

T1 Why do you dilute it?

Sts because it is concentrated.

T1 So what do we mean by concentration?

St1 A ratio at which a substance is contained in a solution.

T1 What is a substance? For example, in a sugar solution, there is water and sugar. T1 then drew the diagram in Fig. 2.

T1 (continues) So, in this case what is the substance?

Sts Sugar.

T1 The sugar is then called a solute. What we are looking for as concentration is the amount of solute in $1 \mathrm{dm}^{3}$ of solution.

The extract above illustrates an effort by $\mathrm{T} 1$ to place the subject into context. T1 used a commonly known drink, Oros, which is a concentrated fruit juice many learners may be familiar with, which normally requires dilution with water before drinking. T1 uses it to introduce the chemistry concept of concentration, which is an attempt to make the concept understandable.

T3 used an analogy of a number of people occupying known volume to introduce concentration. Although students struggled to appreciate the analogy $\mathrm{T} 3$ used the analogy to explain the concept.

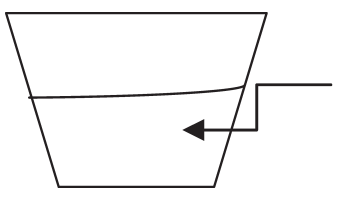

\section{Sugar and water}

Figure 2 T1's illustration of sugar solution. 
The second category was when the teachers solved or asked students to solve problems. In the extract below T3 uses a problem to explain the concept of volume of gases.

T3 ...At room temperature and pressure, the volume of a gas occupies $24 \mathrm{dm}^{3}$ or litres. Room temperature is $25^{\circ} \mathrm{C}$ and pressure is $1 \mathrm{atmosphere} \mathrm{(atm).} \mathrm{The} \mathrm{atomic} \mathrm{mass} \mathrm{of} \mathrm{nitrogen}$ is 14 and for nitrogen gas $\left(\mathrm{N}_{2}\right)$ we add $14+14=28 \mathrm{~g} \mathrm{~mol}^{-1}$. So if we get $24 \mathrm{~L}$ of nitrogen molecules with the mass of $28 \mathrm{~g} \mathrm{~mol}^{-1}$ that will contain one mole. Is that clear?

Sts (in chorus) no sir.

T3 OK let me make an example. (writes a problem on the board) How much volume of carbon dioxide is occupied by 0.2 moles of carbon dioxide at room temperature and pressure (r.t.p)?

T3 (continues) The reason why we talk about r.t.p is because when gases are heated, they expand and occupy a larger volume and when cooled they contract and occupy a smaller volume. So we say: (writes on the board)

$1 \mathrm{~mol}=24 \mathrm{~L}$

(As he writes) So now we have 0.2 moles $=\mathrm{X}$

So this is a ratio problem. You just have to cross multiply to get the answer. (writes on the board)

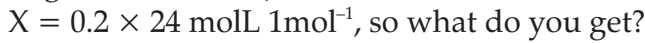

Sts 4.8 .

The calculations above were intended to explain how to solve problems involving volumes of gases which appears to be an effort, on the part of T3, to make the concept easy for students to understand.

The following extract shows what happened in T1's lesson

T1 (wrote the questions on the board) You have to discuss the questions amongst yourselves so that we can talk about them later. Or you can write down your responses for me to check on them to see if you do understand.

Sts (formed groups to discuss the questions).

T1 (moved around the classroom to check students' responses) I have seen that some of you are getting question three correct. Since many of you got question three correct let me give you another question. (wrote question 4 on board, students still discussing. The teacher continued to move around checking what students were doing and explaining to those who had difficulties)

T1 To answer question 3 do we have to say:

$1 \mathrm{~mol}=160$

$0.5 \mathrm{~mol}=\mathrm{X}$

Sts (in chorus) no.

T1 Is 0.5 given here, the number of moles?

St2 no it is the concentration.

T1 Then what do you have to do?

St2 find the number of moles first.

T1 How do you do that?

St2 $($ wrote on the board $)$ concentration $=$ moles $/$ Volume $0.5=\mathrm{X} / 0.1 \mathrm{dm}^{3}$

$=0.5 \times 0.1$

$=0.05$ moles

In this extract $\mathrm{T} 1$ did two things with the intention to make concepts understandable. The first was to give students chance to practice solving problems involving concentration. The second was to ask one student to show struggling students how to solve a given problem.

It is important to note that in both categories of making the concepts of stoichiometry easy, the teachers dominated the lessons and students responded to lower order questions, except in instances where they had to solve problems.

What teachers did to make concepts of stoichiometry easy was also determined from their descriptions of what they do when teaching stoichiometry. Teachers were asked about how they make the concepts of stoichiometry easy to understand during their teaching. Different issues surfaced from the teachers' responses. T1 said he breaks the topic into much simpler components that could enable students to easily understand the topic. The conversation with the first researcher went as follows:

$\mathrm{R}$ how do you make concepts of stoichiometry easy to understand?

T1 well if that is making it easier to understand, I try to break down the topic by teaching about moles; that is, calculating moles from given mass of substances, eh...teaching about volume of gases...I mean about volumes of gases, teaching about eh, concentration of solutions in both moles per decimeter and grams per decimeter and then calculate from equations, eh now bringing all those things in the equations.

$\mathrm{R}$ OK Sir! So breaking down the concepts like that makes it easy to understand?

T1 (laughing) I hope so.

A number of issues can be noted in this extract. Firstly, T1 believes that there are some concepts that should be treated before others. He claims to start with moles, then volumes followed by concentration and equations. Secondly, T1 is not sure if this is making the topic easy.

The response of $\mathrm{T} 2$ is similar to that of $\mathrm{T} 1$ in that it highlights the issue of breaking down the topic. The discussion with the researcher on the same matter went as follows.

T2 I tackle each concept per lesson. Like if I am talking about moles. If I am referring to the relationship between moles and grams, I only do that concept in a lesson. In the next lesson, maybe I will talk about moles and particles.

$\mathrm{R}$ So tackling each concept at a go means the students may not get confused?

T2 Yes.

The extract has connotations of breaking down the topic into its sub-topics. But, and perhaps more importantly, T2 emphasizes the notion of dealing with one concept per lesson as a way of making the topic easy.

According to T3 sequencing of the lesson is critical in making students understand the relationship between different concepts that make up a topic. The discussion with the researcher went as follows:

T3 OK, yah I think stoichiometry is taught somewhere after looking at the formulae, things like those. Just before eh, we teach stoichiometry, there are topics which are pre, which are required first so that when they get to stoichiometry then everything is at least easier. That's the only way; I think we sort of try to link eh, stoichiometry with other topics that we treat before stoichiometry so that it becomes a bit understandable.

$\mathrm{R}$ OK. What happens then when you are in the middle of the topic, how do you start the topic in such a way that...

T3 ...we normally start with things which, which, which can be connected to things which are going to be done, eh...in in in the following lessons...yah...so for instance, if I, if we talk about chemical equations and how...the things we can learn from them, then the following...in the following lesson we treat... maybe how to calculate moles, to calculate eh... the required quantities from given equations. In other words, I think it's just...making everything related, so that there is no subtopic or any concept that will be isolated from the, from the others.

The extract above brings to the fore two ideas to simplify the topic of stoichiometry. Firstly, T3 says he teaches other topics 
he considers prerequisite to stoichiometry first with the hope that this will make stoichiometry concepts easy to understand. Secondly, he also subscribes to the notion of breaking down the topic into smaller sections.

\section{Discussion}

This study was aimed at finding out how chemistry teachers transform and represent subject matter for purposes of promoting conceptual understanding. It was conducted in the context where teaching remains heavily dominated by teachers while students are expected to sit and listen quietly to the teacher. Important findings arose from the analysis above.

The first issue that emerged, relates to the process of making concepts understandable to students and its impact on the choice of teaching strategies which is central in Shulman's notion of PCK. ${ }^{13}$ According to Mavhunga and Rollnick this process includes the notion of curricular saliency which encompasses the process of breaking down a topic into smaller units called 'Big Ideas' and rearranging them to allow effective teaching. ${ }^{14}$ All teachers in this study reflected on this process even though the intentions were not clearly mentioned as allowing effective teaching. Another consideration, as suggested by Mavhunga and Rollnick, is whether the choice of teaching strategies is influenced by making concepts understandable. The analysis above shows that there is minimal effort from all the teachers to make concepts understandable to students. For instance, T1, when justifying his choice of teaching strategies, acknowledges that '...the topic is too abstract' but does not show how lecturing makes concepts easy. T1 believes that 'telling' students is enough to address the abstract nature of stoichiometry concepts. The second consideration is whether their actual practice reflects effort to make concepts easy. Observation data reflected efforts to make the concepts easy during lessons although it is noted that the lessons remained dominated by the teachers. For, instance, the two teachers, T1 and T3, used analogies to introduce the concept of concentration. Research carried out in Lesotho shows this trend where teachers dominate lessons and, importantly, teachers being aware that teacher-centred strategies pose challenges to students to understand the content. ${ }^{26}$ The role of students and the teacher is another important indicator of the teaching of science. The data presented above show that students' role was predominantly that of answering the teacher's questions and taking notes from the chalk board. The teacher explained concepts, wrote summaries of what was explained on the chalkboard and asked students questions. Literature on the teaching of chemistry suggests that students may not find stoichiometry concepts easy if taught this way. ${ }^{22}$

The second issue is how teachers conceptualized the topic in terms of identification of big ideas and factors that contributed to that conceptualization. The data above show that different explanations were given about the origin of big ideas. These included the syllabus, textbooks, and experience. None of the teachers related big ideas to students' learning and the attempt to simplify the topic. Breaking down a topic into big ideas demonstrates knowledge of subject matter and the interrelationships between concepts of a topic. Literature has suggested that unpacking content knowledge into big ideas helps the teacher to '...teach in ways that have a clear purpose and focus in developing a conceptualization of the subject area...'. ${ }^{13}$ The fact that students' understanding of the various abstract concepts in stoichiometry is problematic, calls for consideration of what constitutes big ideas of stoichiometry by teachers.

The last issue relates to the issue of blending of knowledge areas as an effort to make concepts understandable. The data above show minimal bringing together of different teacher's knowledge areas such as knowledge of curriculum to make concepts of stoichiometry easy to understand.

\section{Conclusions}

This study shows that chemistry teachers turn to teachercentred approaches with minimal effort to transform the concepts for students to be able to understand them which confirms the similar findings in relation to physics teachers at the same level. ${ }^{26}$ The teaching strategies that teachers suggested as suitable for teaching chemistry concepts are, in many cases, not influenced by making concepts simple. Teachers in this study recognize the need to break the topics into smaller units although it is not clear if they do so with the purpose of simplifying the concepts. For instance, on the one hand, teachers used analogies to introduce concentrations. This use of analogies plays an important role in simplifying the concepts. ${ }^{14}$ But on the other hand, teachers dominate the lessons. Their notion of big ideas of a topic is influenced by factors such as syllabus, examinations and textbooks. From the description of transformation of scientific concepts by Mavhunga and M. Rollnick. ${ }^{14}$ it is understandable that many students in Lesotho will find chemistry difficult and thus their performance will remain weak.

Literature on PCK has highlighted a number of important lessons regarding the teaching of science that includes the transferability of PCK ${ }^{14}$ and the topic specificity of PCK. This study employed PCK as a theoretical tool to understand the teachers' thinking, practice and the possible contribution to achievement in the Lesotho context. The focus on PCK added an important qualitative perspective on which knowledge areas are lacking in the teachers practice and explaining why students may not understand the chemistry concepts. These knowledge areas that require attention include the process of transformation of concepts and the choice of appropriate teaching methods. It is therefore recommended that the Ministry of Education and Training and institutions of higher learning such as National University of Lesotho and Lesotho College of Education organize in-service programmes to assist teachers with how to teach challenging topics such as stoichiometry. Recent literature suggests that such programmes must include, as one of their critical features, pre- and post-development of CoRes of a concerned science topic. ${ }^{27}$ This results from an observation that predevelopment of CoRes encourages science teachers to critically think about the content during the intervention. ${ }^{27}$

\section{${ }^{5}$ ORCID ID}

M. Qhobela: (iD) orcid.org/0000-0001-9071-6843

\section{References}

1 M.O. Martin, I. V. Mullis, P. Foy and G. M. Stanco, TIMSS 2011 International Results in Science. TIMSS \& PIRLS International Study Center, Lynch School of Education, 2012, Boston College Chestnut Hill, MA, USA.

2 A.C. Austin, H. Ben-Daat, M. Zhu, R. Atkinson, N. Barrows and I.R. Gould, Measuring student performance in general organic chemistry, Chem. Educ. Res. Prac., 2015, 16, 168-178.

3 M. Lekhetho, Stakeholder perceptions about factors that cause poor student performance in Cambridge Overseas School Certificate (COSC) examinations in Lesotho, Int. J. Edu. Sci., 2013, 5(4), 385-395.

4 V. Reddy, Mathematics and Science Achievement in South African Schools in TIMSS 2003, 2006, HSRC Press, Cape Town.

5 T. Maqutu, Explaining success in O-level physical science in Lesotho: a survey of physical science teachers, Afr. J. Res. MST. Educ., 2003, 7, 97-107.

6 M. Qhobela and E.K. Moru, Learning physics through argumenta- 
tion at secondary school level in Lesotho: a feasible teaching strategy? Afr. J. Res. MST. Educ., 2011, 15(2), 97-111.

7 M.K. Kanime, An Investigation into how Grade 11 Physical Science Teachers Mediate Learning of the Topic Stoichiometry: A Case Study, Masters dissertation, Rhodes University, Grahamstown, South Africa, 2015.

8 M.J. George and M. Kolobe, Exploration of the potential of using a virtual laboratory for chemistry teaching at secondary school level in Lesotho, S. Afr. J. Chem., 2014, 67, 113-117.

9 O. Gulacor, T.L. Overton, C.R. Bowman and H. Fynewever, A novel code system for revealing sources of students' difficulties with stoichiometry, Chem. Educ. Res. Prac., 2013, 14, 507-515.

10 A.A., Espinosa, R.C.N., España and A.C. Marasigan, Investigating pre-service chemistry teachers' problem solving strategies: towards developing a framework in teaching stoichiometry, J. Educ. Sci. Environ. Health, 2016, 2(2), 104-124.

11 A.E. Okanlawon, Constructing a framework for teaching reaction stoichiometry using pedagogical content knowledge, Chem., 2010, 19(2), 27-44.

12 S.A. Malcolm, The design and validation of an instrument to measure topic-specific pedagogical content knowledge in stoichiometry of physical sciences teachers, M.Sc. thesis, University of the Witwatersrand, Johannesburg, South Africa, 2015.

13 L.S. Shulman, Those who understand: knowledge growth in teaching, Harvard Educ. Rev., 1987, 57, 1-22.

14 E. Mavhunga and M. Rollnick, Improving PCK of chemical equilibrium in pre-service teachers, Afr. J. Res. MST. Educ., 2013, 17(1-2), 113-125.

15 S. Magnusson, J. Krajcik and H. Borko, Nature, sources and development of pedagogical content knowledge, in Examining Pedagogical Content Knowledge (J. Gess-Newsome \& N.G. Lederman, eds.), Kluwer Academic, Dordrecht, Netherlands, 1999, pp. 95-132.

16 S. Park and J.S. Oliver, Revisiting the conceptualisation of pedagogical content knowledge (PCK): PCK as a conceptual tool to understand teachers as professionals, Res. Sci. Educ. 2008, 38, 261-284.
17 M. Qhobela and E.K. Moru, Examining secondary school physics teachers' belief about teaching and classroom practices in Lesotho as foundation for professional development, Int. J. Sci. Math. Educ., 2014, 12, 1367-1392.

18 J. Loughran, P. Mulhall and A. Berry, In search of pedagogical content knowledge in science: developing ways of articulating and documenting professional practice, J. Res. Sci. T, 2004, 41(4), 370-391.

19 B. Davidowitz, G. Chittleborough and E. Murray, Student-generated submicro diagrams: a useful tool for teaching and learning chemical equations and stoichiometry, Chem. Educ. Res. Prac., 2010, 11, 154-164.

20 A.H. Johnstone, Chemical education research in Glasgow in perspective, Chem. Educ. Res. Prac., 2006, 7(2), 49-63.

21 D. Gabel, Improving teaching and learning through chemistry education research: a look to the future, J. Chem. Educ., 1999, 76(4), 548-554.

22 K.L. Evans, D. Yaron and G. Leinhardt, Learning stoichiometry: e comparison of text and multimedia formats, Chem. Educ. Res. Prac., 2008, 9, 208-218.

23 A.H. Johnstone, Chemistry teaching - science or alchemy? 1996 Brasted lecture, J. Chem. Educ., 1997, 74(3), 262-268.

$24 \mathrm{~V}$. Kind, Pedagogical content knowledge in science education: perspectives and potential for progress, Stud. Sci. Educ., 2009, 45(2), 169-204.

25 A.N. Geddis, B. Onslow, C. Beynon and J. Oesch, Transforming content knowledge: learning to teach about isotopes, Sci. Educ., 1993, 77(6), 575-591.

26 M. Qhobela and E.K. Moru, Understanding challenges physics teachers come across as they implement learner-centred approaches in Lesotho, Afr. J. Res. MST. Educ., 2014, 18(1), 63-74.

27 P. Pitjeng-Mosabala and M. Rollnick,. Exploring the development of novice unqualified graduate teachers' topic-specific PCK in teaching the particulate nature of matter in South Africa's classrooms, Int. J. Sci. Educ., 2018, 40(7), 742-770. 